Vol. 11 (3): 653-658 (2021)

\title{
A RARE CAUSE OF DEATH FROM SNAKE BITE POISONING: CASE REPORT
}

\author{
Esmeralda Thoma ${ }^{1}$, Lordian Nunci ${ }^{2}$, Armela Priftaj $^{3}$, Sonila Bitri $^{4}$, Enkeleda Shkurti $^{3}$ \\ ${ }^{1 *}$ University Hospital Center "Mother Teresa", Clinical toxicology and addictology service, Tirana, Albania; \\ ${ }^{2}$ University Hospital Center "Mother Teresa", Intensive Care Service, Tirana, Albania; \\ ${ }^{3}$ University of Medicine of Tirana, Tirana, Albania; \\ ${ }^{4}$ American Hospital 2, Tirana, Albania;
}

*Corresponding Author Esmeralda Thoma, e-mail: esmeraldahoxha@yahoo.com;

Received April 2021; Accepted May 2021; Published June 2021;

DOI: $\underline{\text { https://doi.org/10.31407/ijees11.339 }}$

\begin{abstract}
Snake-bite is a well known occupational hazard, especially among farmers and other outdoor workers, and among those who live ground floor houses. Snake bites are usually clinically pictured with neurological, hematological and vascular damage. Cardiac manifestations from snake bike are not prominent. Snake bite after recovering from aluminium phosphide poisoning is yet more rare. Herein we present a rare case of death from a snake bite from one patient who previously survived a deliberately aluminium phosphide poisoning. The patient, a male 45 years old was presented to the emergency department with a slighty swollen leg from a snake bite, two days after he was discharged from hospital for a diagnosis of "Aluminium phosphide poisoning". On inspection, fang marks were identified on the medial malleolus of the right leg. On arrival, the patient was conscious, feared, restless, hypotensive, with a weak peripheral pulse. He complains for severe pain along his limb. General examination revealed: afebrile, HR 134/min, BP 90/60 mmHg, RR 21/min. Because of the patient`s previous and actual medical history, the patient was transferred in ICU for intensive care. After 36 hours he died.
\end{abstract}

Key words: snake, bite, AlP poisoning, death. 